\title{
Robust Auto-tuning Fractional Order Control of an Aerodynamical System
}

\author{
Eva-H Dulf $^{1 *}$, Cristina-I. Muresan ${ }^{1}$, Roxana Both-Rusu ${ }^{1}$ and Francisc-V. Dulf ${ }^{2}$ \\ ${ }^{1}$ Department of Automation, Technical University of Cluj-Napoca, Romania \\ ${ }^{2}$ University of Agricultural Sciences and Veterinary Medicine Cluj-Napoca \\ ${ }^{*}$ Corresponding author
}

\begin{abstract}
The present paper's goal is to offer to the user a method which are similar to the "Plug and Play" idea in the world of "Control": the auto-tuning control structure of a twinrotor aerodynamical system, a highly nonlinear, multi input multi output system. Knowing the fact that in industrial applications PID controllers are widely used, the authors uses a generalized PID: a fractional order PID controller. The controller parameters are tuned based on a novel, simplified algorithm using vector theory. Experimental results using a laboratory scale equipment reveal that the suggested control approach is effective and near optimal.
\end{abstract}

Keywords-fractional order control; auto-tuning control structure; twin-rotor system

\section{INTRODUCTION}

In the last decade fractional calculus and the use of fractional calculus in control theory is widely studied and used in the research due to their proved advantages [1-5]. PID controllers being the most popular controllers, the interest for such a controller, but having more flexibility is obvious. Fractional order PID controllers representing a generalization of classical PID controllers [6], with two more degree of freedom in comparison with a classical PID controller, are more and more studied and discussed for various industrial applications. On the other hand there is an increased interest in auto-tuning control methods to be more autonomous, to handle process variations, which may arise for different reasons.

The present research focuses on the control of a benchmark problem of Control Systems: a twin-rotor system. This process is a highly nonlinear, complex MIMO system, being widely studied by several researchers. In [7] are presented the results of a $\mathrm{H} \infty$ controller design considering uncertainties due to the differences between the linearized mathematical model and the actual system, disturbance and the model order reduction during the derivation of the linear fractional transformation model. In [8] the tuning of a centralized cross-coupled PID controller based on simulated annealing optimization is discussed. In [9] a set-point weighted fractional order PID controller is proposed. Moreover, to ensure the desired closedloop performance, a fractional order pre-filter is applied. The paper of [10] presents a procedure for parametric uncertainty modeling of this highly nonlinear MIMO cross coupled system with the final goal of linear fractional transformation model realization. In [11] is detailed a model of this twin rotor system in terms of vertical one-degree-of-freedom (1DOF), horizontal $1 \mathrm{DOF}$, and two-degree-of-freedom (2DOF) dynamics using
Newtonian as well as Lagrangian methods. A nonlinear model of the system is depicted in [12], using state space neural networks with delays. In [13] two fractional order controllers for the twin-rotor aerodynamic system based on a Particle Swarm Optimization (PSO) algorithm are designed. Adaptive and auto-tuning control is applied with success by the authors for other experimental plants [14].

Nowadays computer sciences facilitated user's life with the famous "Plug and Play". The same facility is expected for control systems. Such a control structure is proposed in the present work. It is used a novel, simplified algorithm of fractional order controller design, based on vector theory [15], included in an auto-tuning control scheme.

The paper is structured in four parts dealing with introductory aspects, the proposed fractional order controller design method, the auto-tuning control schemes, experimental results and concluding remarks.

\section{The CONTROL Structure}

It is considered the transfer function of the fractional order PI controller of form

$$
\mathrm{C}(\mathrm{s})=\mathrm{K}_{\mathrm{p}}+\mathrm{K}_{\mathrm{d}} \mathrm{s}^{-\lambda}
$$

for which the frequency domain equation is

$$
C(j \omega)=K_{p}+K_{d}(j \omega)^{-\lambda}
$$

Obviously, such fractional order PI controller has one more degree of freedom in comparison with classical, integer order PI controllers.

In the present work the parameters of the fractional order controller are established based on the equations corresponding to the performances as the gain crossover frequency:

$$
\left|C\left(j \omega_{g c}\right) \cdot P\left(j \omega_{g c}\right)\right|=0 d B
$$

phase margin:

$$
\angle\left(C\left(j \omega_{g c}\right) \cdot P\left(j \omega_{g c}\right)\right)=-\pi+\varphi_{m}
$$


and robustness to gain variations, imposed as flat phase evolution around the gain crossover frequency:

$$
\left.\frac{\mathrm{d}}{\mathrm{d} \omega} \angle(\mathrm{C}(\mathrm{j} \omega) \cdot \mathrm{P}(\mathrm{j} \omega))\right|_{\omega=\omega_{\mathrm{cg}}}=0
$$

where with $P$ is noted the process model.

Denoting the proportional term of this controller as a vector $\left|z_{1}\right|=K_{p}$ and the integral term as a vector $\left|z_{2}\right|=K_{d}(j \omega)^{-\lambda}$, the vector form of the fractional order PI controller, the vector $\left|\mathrm{z}_{1}+\mathrm{z}_{2}\right|$ can be represented as in Figure I.

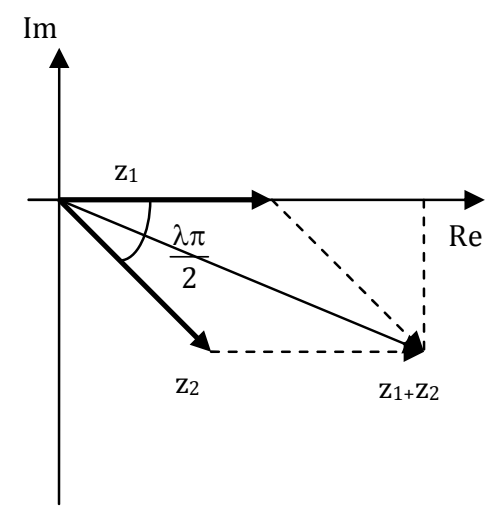

FIGURE I. THE VECTOR FORM OF A FRACTIONAL ORDER PI CONTROLLER

Using classical geometry equations it can be obtained:

$$
\begin{gathered}
\angle \mathrm{z}_{1}, \mathrm{z}_{2}=\angle \mathrm{K}_{\mathrm{i}}(\mathrm{j} \omega)^{-\lambda}-\angle \mathrm{K}_{\mathrm{p}}= \\
=\angle \mathrm{K}_{\mathrm{i}} \omega^{-\lambda}\left(\cos \frac{\lambda \pi}{2}-\mathrm{j} \sin \frac{\lambda \pi}{2}\right)-\angle \mathrm{K}_{\mathrm{p}}= \\
=\operatorname{arctg}\left(-\frac{\mathrm{K}_{\mathrm{i}} \omega^{-\lambda} \sin \frac{\lambda \pi}{2}}{\mathrm{~K}_{\mathrm{i}} \omega^{-\lambda} \cos \frac{\lambda \pi}{2}}\right)= \\
=\operatorname{arctg}\left(-\operatorname{tg}\left(\frac{\lambda \pi}{2}\right)\right)=-\frac{\lambda \pi}{2} \\
\sin \angle\left(\mathrm{z}_{1}+\mathrm{z}_{2}\right)=\frac{\left|\mathrm{z}_{2}\right| \cdot \sin \angle \mathrm{z}_{1}, \mathrm{z}_{2}}{\left|\mathrm{z}_{1}+\mathrm{z}_{2}\right|}=\frac{\left|\mathrm{z}_{2}\right| \cdot \sin \left(-\frac{\lambda \pi}{2}\right)}{\left|\mathrm{z}_{1}+\mathrm{z}_{2}\right|}
\end{gathered}
$$

and

$$
\left|z_{1}+z_{2}\right|^{2}=\left|z_{1}\right|^{2}+\left|z_{2}\right|^{2}+2 \cdot\left|z_{1}\right| \cdot\left|z_{2}\right| \cdot \cos \angle z_{1}, z_{2}
$$

Using these results in equations (3)-(5), it is obtained:

$$
\mathrm{K}_{\mathrm{p}}{ }^{2}+2 \mathrm{~K}_{\mathrm{p}} \mathrm{K}_{\mathrm{i}} \omega_{\mathrm{gc}}^{-\lambda} \cdot \cos \frac{\lambda \pi}{2}+\mathrm{K}_{\mathrm{i}}^{2} \omega_{\mathrm{gc}}^{-2 \lambda}=\frac{1}{\left|\mathrm{P}\left(\mathrm{j} \omega_{\mathrm{gc}}\right)\right|}
$$

$$
\sin ^{-1}\left(\frac{-\mathrm{K}_{\mathrm{i}} \omega_{\mathrm{gc}}^{-\lambda} \cdot \sin \frac{\lambda \pi}{2}}{\sqrt{\mathrm{K}_{\mathrm{p}}^{2}+\mathrm{K}_{\mathrm{i}}^{2} \omega_{\mathrm{gc}}^{-2 \lambda}+2 \mathrm{~K}_{\mathrm{p}} \mathrm{K}_{\mathrm{i}} \omega_{\mathrm{gc}}^{-\lambda}} \cdot \cos \frac{\lambda \pi}{2}}\right)=\mathrm{a}
$$

with $\mathrm{a}=-\pi+\varphi_{\mathrm{m}}-\angle \mathrm{P}\left(\mathrm{j} \omega_{\mathrm{gc}}\right)$

$$
\begin{aligned}
& \frac{\mathrm{d}}{\mathrm{d} \omega} \sin ^{-1}\left(\frac{-\mathrm{K}_{\mathrm{i}} \omega_{\mathrm{gc}}^{-\lambda} \cdot \sin \frac{\lambda \pi}{2}}{\sqrt{\mathrm{K}_{\mathrm{p}}^{2}+\mathrm{K}_{\mathrm{i}}^{2} \omega_{\mathrm{gc}}^{-2 \lambda}+2 \mathrm{~K}_{\mathrm{p}} \mathrm{K}_{\mathrm{i}} \omega_{\mathrm{gc}}^{-\lambda} \cos \frac{\lambda \pi}{2}}}\right)= \\
& =-\frac{\mathrm{d}}{\mathrm{d} \omega} \mathrm{P}\left(\mathrm{j} \omega_{\mathrm{gc}}\right)
\end{aligned}
$$

Solving the resulted nonlinear equations system yields:

$$
\mathrm{K}_{\mathrm{i}}=\frac{\mid \mathrm{P}\left(\mathrm{j} \omega_{\mathrm{gc}}\right) \cdot \sin \left(-\pi+\varphi_{\mathrm{m}}\right)}{\omega_{\mathrm{gc}}^{-\lambda} \cdot \sin \left(-\frac{\lambda \pi}{2}\right)}
$$

and

$$
\begin{aligned}
& \mathrm{K}_{\mathrm{p}}=-\mathrm{K}_{\mathrm{i}} \omega_{\mathrm{gc}}^{-\lambda} \cdot \cos \left(-\frac{\lambda \pi}{2}\right) \pm \\
& \pm \sqrt{\mathrm{P}\left(\mathrm{j} \omega_{\mathrm{gc}}\right)^{2}-\mathrm{K}_{\mathrm{i}}^{2} \omega_{\mathrm{gc}}^{-2 \lambda} \cdot \sin ^{2}\left(-\frac{\lambda \pi}{2}\right)}
\end{aligned}
$$

The controller parameter tuning algorithm can be used as follows:

Step 1: Are imposed the performance measures: gain crossover frequency and phase margin

Step 2: In a repeating loop, for different values of the fractional order $(\lambda \in(0,1))$, are computed the parameters $\mathrm{K}_{\mathrm{i}}$ and $K_{p}$ from the equations (12) and (13) and checked the validity of equation (11) till all these criteria are met.

The designed fractional order controller is included in an auto-tuning control structure, as presented in Figure II [16]. 


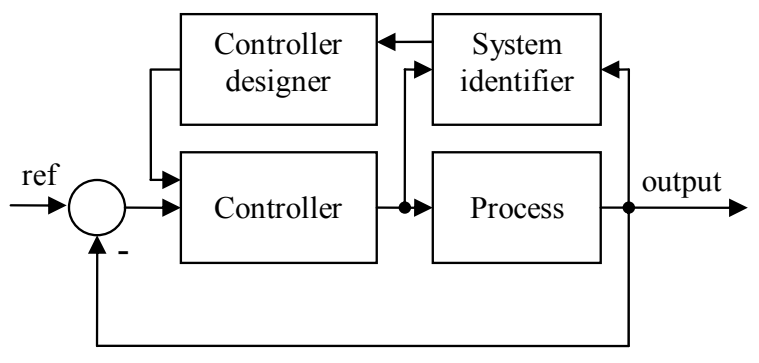

FIGURE II. THE USED AUTO-TUNING CONTROL STRUCTURE

The "System identifier" block uses a recursive simple leastsquares (RLS) algorithm to estimate the system parameters. In the "Controller designer" subsystem the fractional order controller is tuned based on the new parameter values, following the procedure described above. In the "Controller" block is obtained the command signal recursive equation corresponding to the designed fractional order controller.

\section{RESUlTS AND DisCUSSION}

The experiments were carried out using the twin-rotor aerodynamical system from Inteco [17], which behaviour in certain aspects resembles that of a helicopter, Figure III.

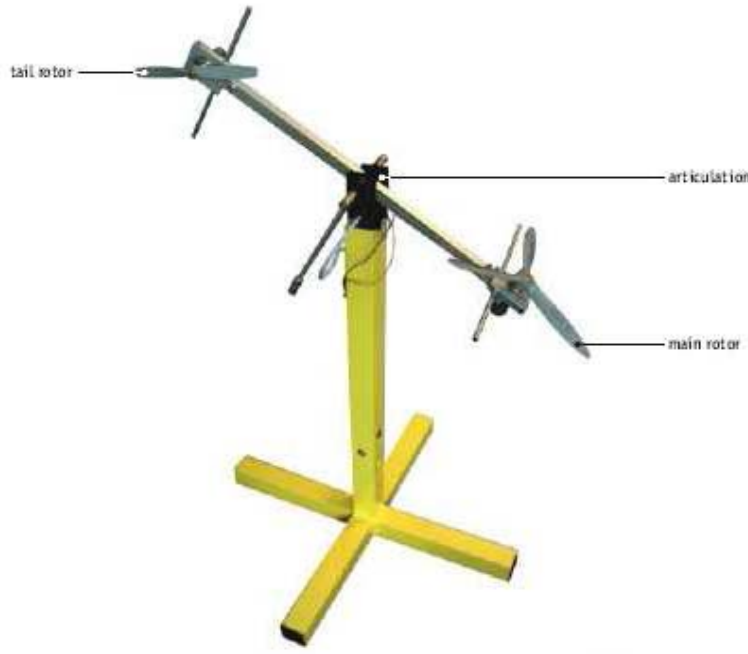

FIGURE III. THE TWIN-ROTOR MULTI-INPUT MULTI-OUTPUT LABORATORY SCALE PROCESS (www.inteco.com.pl)

This experimental setup consists in a beam joined to its base with an articulation with both ends having two propellers driven by DC motors. The articulated joint allows the beam to rotate in such a way that its ends move on spherical surfaces. There is a counter-weight fixed to the beam and it determines a stable equilibrium position. The controls of the system are the motor supply voltages.

To set up the auto-tuning control blocks, in order to use the corresponding equations both for identification and controller design block, the authors established a linearized mathematical model of the equipment using classical experimental identification methods. The obtained model is depicted in Figure IV.

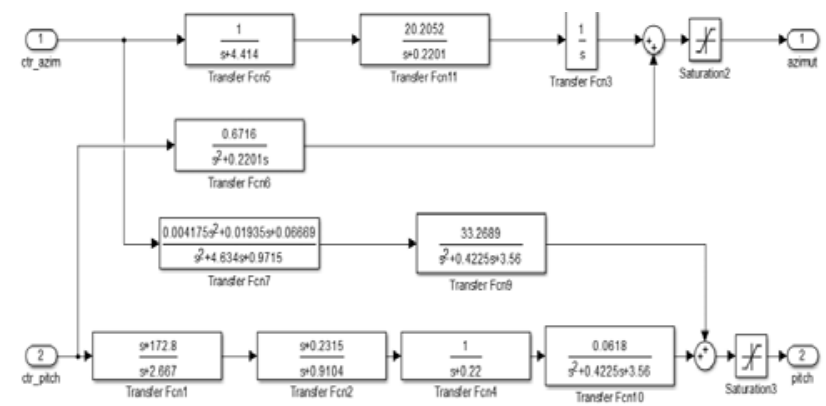

FIGURE IV. THE BLOCK DIAGRAM OF THE LINEARIZED SYSTEM

With the obtained model structures, using the apriori obtained parameters as initial conditions, were defined the recursive identification equations for both subsystems. The same structures were used for the controller parameter tuning equations, in the above described algorithm. The fractional order controller implementation is realized using the nipid block from ninteger toolbox [18]. For simplicity in Figure $\mathrm{V}$ is presented the control structure only for one subsystem, the second one having the same structure.

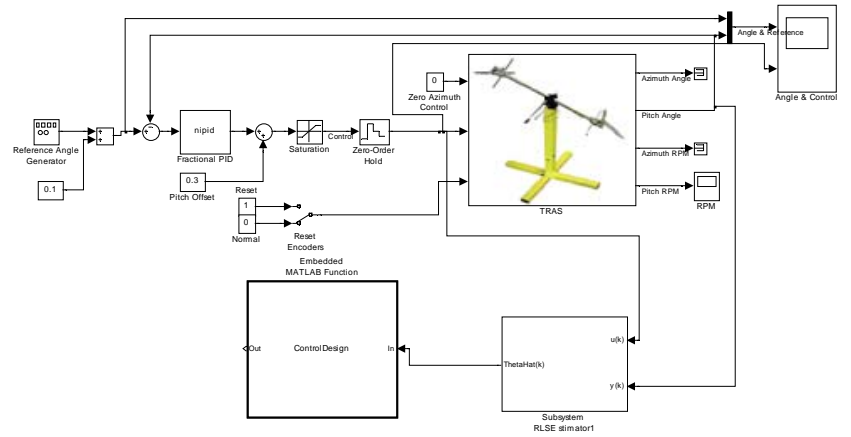

FIGURE V. IMPLEMENTATION OF THE AUTO-TUNING CONTROL STRUCTURE (SUBSYSTEM OF PITCH CONTROL)
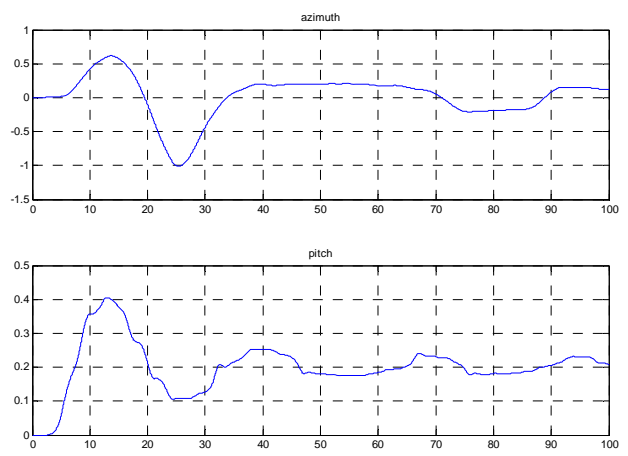

FIGURE VI. SYSTEM OUTPUTS FOR STEP PITCH REFERENCE

In order to test the implemented control structure, it was applied a step reference signal for the vertical angle of 0.2 radians, while the horizontal reference is null. The experimental results are presented in Figure VI, highlighting a 
good reference tracking, but with a large overshoot at the beginning.

For a null pitch reference signal and a -1 radian step signal for azimuth the experimental results are presented in Figure VII. The results reveal a good reference tracking, but with the same large overshoot at the beginning of the experiment.
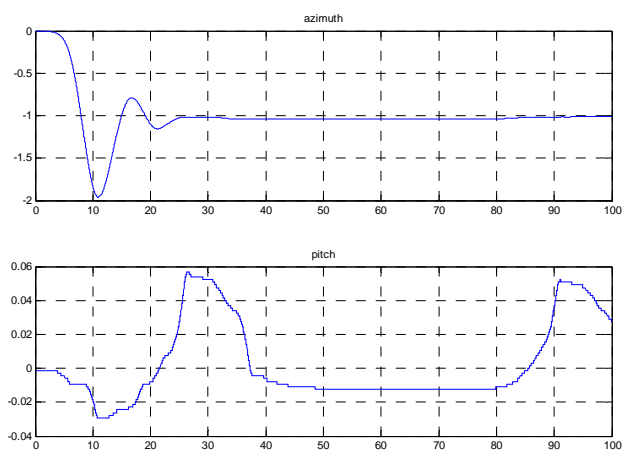

FIGURE VII. SYSTEM OUTPUTS FOR STEP AZIMUTH REFERENCE

Applying step reference signals on both inputs (-1 radian for azimuth and 0.2 radians for pitch), the closed loop system presents good performances, even in this case, when interaction between the control loops is more pronounced, Figure VIII.
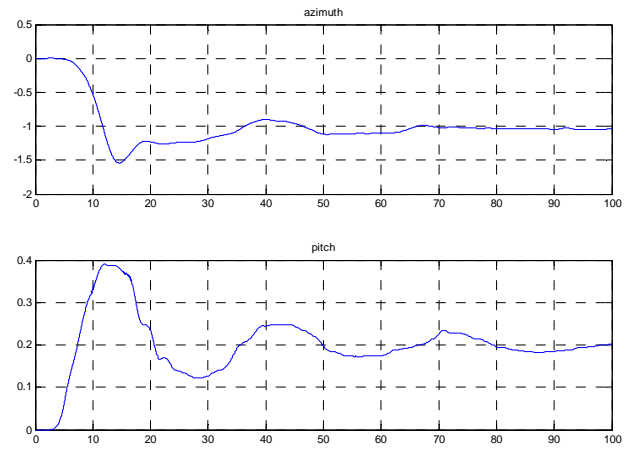

FIGURE VIII. SYSTEM OUTPUT APPLYING BOTH AZIMUTH AND PITCH REFERENCE

\section{CONCLUSIONS}

Auto-tuning provides efficient responses, suitable and viable for the case study of the aerodynamical twin-rotor system. All of these advantages can be obtained by a user without any knowledge in the field of control, following the "Plug and Play" facilities trends of all systems. The novelty of the auto-tuning structure is the use of a fractional order controller. The controller parameters tuning algorithm is a novel approach, based on vector geometry.

\section{ACKNOWLEDGMENT}

This work was supported by a grant of the Romanian National Authority for Scientific Research, CNDI- UEFISCDI, project number PN-II-RU-TE-2012-3-0307, contract 38/2015.

\section{REFERENCES}

[1] C. A.Monje, Y. Q. Chen, B. M Vinagre., D. Xue, V. Feliu, "Fractional Order Systems and Control - Fundamentals and Applications". Advanced Industrial Control Series, Springer-Verlag, London, 2010.

[2] E.H Dulf., C.I.Pop, and F.V. Dulf, „Fractional calculus in 13C separation column control". Signal, Image and Video Processing, 6(3): 479-485., 2012.

[3] E.H.Dulf, C.I.Muresan, and M. L.Unguresan. „Modeling the (15N) isotope separation column". Journal of Mathematical Chemistry, 52(1):115-131, 2014.

[4] E.H.Dulf, F.V.Dulf and C.I. Pop C.I, „Fractional Model of the Cryogenic (13C) Isotope Separation Column", Chemical Engineering Communication, 202(12): 1600:1606, 2015.

[5] C.I. Muresan, Eva-H. Dulf, et al., "Microcontroller Implementation of a Multivariable Fractional Order PI Controller", 19th International Conference on Control Systems and Computer Science, 2013, 44-51

[6] I. Podlubny I., "Fractional-order systems and PI $\lambda \mathrm{D} \mu$-controllers", IEEE Transactions on Automatic Control. 44 (1): 208-214. 1999.

[7] T. Roy, Barai R.K., "LFT modelling and $\mathrm{H} \infty$ control of a non-linear MIMO system with cross coupled dynamics", Int. J. of Automation and Control, 7(1/2): 105 - 133., 2013.

[8] M. Moness, Moustafa A.M. "Tuning a digital multivariable controller for a lab-scale helicopter system via simulated annealing and evolutionary algorithms", Transactions of the Institute of Measurement and Control, 37(10):1254-1273, 2015

[9] T. Roy, Barai R.K, "Control Oriented LFT Modeling of a Non Linear MIMO system", International Journal of Electrical, Electronics and Computer Engineering ,1(2): 15-21, 2012

[10] A. Rahideh, Shaheed M. H., "Mathematical dynamic modelling of a twin-rotor multiple input-multiple output system", Proceedings of the Institution of Mechanical Engineers, Part I: Journal of Systems and Control Engineering, 221(1): 89-101, 2007.

[11] R. Azarmi, Tavakoli-Kakhki M., Khaki Sedigh A. and Fatehi A, "Analytical Design of Fractional Order PID Controllers Based on the Fractional Set-point Weighted Structure: Case Study in Twin Rotor Helicopter", Mechatronics, 31: 222-233, 2015

[12] A Czajkowski A, Patan K, "Designing nonlinear model of the Two Rotor Aero-dynamical System using state space neural networks with delays", Proceedings of 18th International Conference on Methods and Models in Automation and Robotics - MMAR 2013, DOI: 10.1109/MMAR.2013.6669905, 195-199., 2013

[13] J. Coelho, Matos Neto R., Lebres C., Santos V., Fonseca Ferreira N. M., SolteiroPires E. J., Tenreiro Machado J. A., "Application of Fractional Algorithms in the Control of a Twin Rotor Multiple Input Multiple Output System", Proceedings of the 2nd Conference on Nonlinear Science and Complexity, Porto, Portugal, 1:12, 2008.

[14] T. Szelitzky, Eva-H. Dulf, "Adaptive control in series load PWM induction heating inverters", International Journal of Electronics, 2013, 100(12): 1714-1723

[15] C.I. Muresan, Eva-H. Dulf, R. Both, "Vector-based tuning and experimental validation of fractional-order PI/PD controllers", Nonlinear Dynamics, 2016, 84(1): 179-188

[16] S. S. Haykin, “Adaptive Filter Theory”, Prentice Hall, 2002.

[17] Two Rotor Aero-dynamical System, User's Manual, www.inteco.com.pl

[18] A. Tepljakov, FOMCON: Fractional-order Modeling and Control, 2012. [Online]. Available: http://www.fomcon.net/ 